\title{
Der früheste bezeugte Augenarzt des klassischen Altertums
}

Von Klaus-Dietrich Fischer

In seiner Abhandlung über den Arzt im Hellenismus hat Fridolf Kudlien kürzlich die Frage nach dem ersten nachweisbaren Augenarzt erneut gestellt $^{1}$. Der folgende Beitrag möchte dem Material bei Kudlien zwei weitere, und zwar ältere Zeugnisse hinzufügen, von denen das zweite wegen des mit ihm verbundenen textkritischen Problems etwas ausführlicher besprochen werden soll.

Der erste Beleg ist eine Grabinschrift von der Via Latina nahe der Porta Latina $^{2}$. Auf ihr wird ein C. Numitorius C. l. Nicanor nationi [sic] Tebaeus medicus ocularius genannt; durch die Angabe C.Caesare dictatore iterum, M. Antonio magistro equitum ist die Inschrift eindeutig auf das Jahr 47 v. Chr. datierbar. Es verdient festgehalten zu werden, daß der Arzt dem von Augenkrankheiten besonders heimgesuchten Ägypten entstammt ${ }^{3}$.

Der zweite Beleg ist literarisch und der Sammlung bemerkenswerter Taten und Aussprüche entnommen, die der römische Schriftsteller Valerius Maximus zur Zeit des Kaisers Tiberius und des medizinischen Schriftstellers Celsus im ersten nachchristlichen Jahrhundert zusammenstellte. Im 15. Kapitel des 9. Buches beschäftigt er sich mit Menschen von niedriger Geburt, die fälschlich vorgaben, einer der vornehmsten Familien zu entstammen. Ein Augenarzt namens Herophilus behauptete, der berühmte C. Marius (an der Wende des ersten vorchristlichen Jahrhunderts mehrmaliger Konsul, Heerführer in den Kämpfen gegen die Kimbern und Teutonen, Anführer der Partei der Popularen und somit in dieser Position Vorgänger C.Iulius Caesars) sei sein Großvater gewesen (Valerius Maximus 9,15,1). Nach dem Bericht des Valerius Maximus brachte er es zu einer Popularität, die der Caesars kaum nachstand, woraufhin Caesar seine Verbannung aus Italien veranlaßte. Als Herophilus nach Caesars Himmelfahrt (wie Valerius sich ausdrückt) nach Rom zurückkehrte, ließ ihn der Senat, dessen Ermordung er (angeblich) geplant hatte, hinrichten. Die Geschichte fällt also just in dieselbe Zeit wie die eingangs besprochene Inschrift. Eine Schwierigkeit ergibt sich dadurch, daß die Handschriften zwischen ocularius und equarius medicus schwanken, Herophilus demnach einmal als Augen-, dann als Tierarzt bzw. Pferdearzt erscheint ${ }^{4}$. Nun war medicus equarius keineswegs 
die gängige Bezeichnung für das, was auf Griechisch schon lange hippiatrós hieß, denn Varro in seinen im Jahre 37 v. Chr. verfaßten drei Büchern über die Landwirtschaft gebraucht dieses Wort nicht. Soweit ich sehe, kommt die Bezeichnung medicus equarius sonst nur im Corpus Inscriptionum Latinarum VI 9610 (= 33 097), in einer Inschrift aus augusteischer Zeit, vor, wo ein gewisser Apollodorus in den Diensten des C. Marius C.f. Tromentina, der mit dem auf Münzen genannten Triumvir identifiziert wird, genannt ist. Er war equarius medicus et venator.

Das textkritische Problem bei Valerius Maximus läßt sich also durch andere zeitgenössische Zeugnisse nicht lösen - es bleibt beim non liquet ${ }^{5}$. Aber wir können feststellen, daß Apollodorus, Herophilus und Nicanor mit ihren ärztlichen Berufen eben zu den Leuten gehörten, die «infimo loco nati» (von niedriger Herkunft) waren.

\section{Anmerkungen}

${ }^{1}$ Fridolf Kudlien, Der griechische Arzt im Zeitalter des Hellenismus. Seine Stellung in Staat und Gesellschaft. Mainz 1979 (Akademie der Wissenschaften und der Literatur. Abhandlungen der geistes- und sozialwissenschaftlichen Klasse 1979: 6), S. 85.

${ }^{2}$ L'Année épigraphique (Revue des publications épigraphiques relatives à l'antiquité romaine) $1972,14$.

${ }^{3}$ So deute ich Tebaeus, ohne behaupten zu wollen, daß die Beziehung auf anderswo gelegene Städte gleichen Namens mit Sicherheit auszuschließen ist. Für das ägyptische Theben sprach sich auch Marcel Le Glay mir gegenüber mündlich aus, dem ich für seinen Rat danke.

4 Thesaurus Linguae Latinae V 2 708, 17-21 (H.G. Wackernagel) s.v. equarius führt beide Lesungen an. Der Beleg aus Valerius Maximus fehlt s.v. ocularius, ibidem IX 2439 , 80-84 (Kuhlmann).

${ }^{5}$ Es geht nicht an, Herophilus ohne weiteres als Tierarzt zu reklamieren, wie es zuletzt Vivian Nutton, Menecrates of Sosandra, Doctor or Vet?, Zeitschrift für Papyrologie und Epigraphik 22 (1976) 93-96, S.94, getan hat. Er fußte wohl auf der Darstellung R.E. Walkers bei Jocelyn M. C. Toynbee, Animals in Roman Life and Art, London 1973, S. 304 und 405, der seinerseits den unkritischen Text bei Reinhard Froehner, Herophilus equarius medicus, Veterinärhistorische Mitteilungen 11 (1931) $35 \mathrm{f}$. benutzt zu haben scheint.

Dr.phil. Klaus-Dietrich Fischer, M.A.

Freie Universität Berlin

Institut für Geschichte der Medizin

D-1 Berlin 45

Gesnerus 3/4 (1980) 